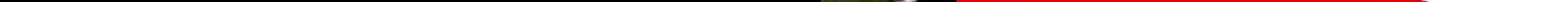


(A) Portada: Pensamientos al atardecer (Universidad Católica de Colombia, Sede Claustro. Bogotá Colombia) Fotografía: Miguel Ángel Capador Niño (Febrero de 2018) macapador08@ucatolica.edu.co
A Orientación editorial

\section{Enfoque y alcance}

La Revista de Arquitectura (ISSN 1657-0308 Impresa y E-ISSN 2357-626X en línea) es una publicación seriada de acceso abierto, arbitrada mediante revisión por pares (doble ciego) e indexada, en donde se publican resultados de investigación originales e inéditos.

Está dirigida a la comunidad académica y profesional de las áreas afines a la disciplina. Es editada por la Facultad de Diseño y el Centro de Investigaciones (CIFAR) de la Universidad Católica de Colombia en Bogotá (Colombia).

La principal área científica a la que se adscribe la Revista de Arquitectura según la OCDE es:

Gran área: 6. Humanidades

Área: 6.D. Arte

Disciplina: 6D07. Arquitectura y Urbanismo

También se publican artículos de las disciplinas como 2A02, Ingeniería arquitectónica; 5G03, Estudios urbanos (planificación y desarrollo); 6D07, Diseño.

Los objetivos de la Revista de Arquitectura son:

- Promover la divulgación y difusión del conocimiento generado a nivel local, nacional e internacional

- Conformar un espacio para la construcción de comunidades académicas y la discusión en torno a las secciones definidas.

- Fomentar la diversidad institucional y geográfica de los autores que participan en la publicación.

- Potenciar la discusión de experiencias e intercambios científicos entre investigadores y profesionales.

- Contribuir a la visión integral de la arquitectura, por medio de la concurrencia y articulación de las secciones mediante la publicación de artículos de calidad.

- Publicar artículos originales e inéditos que han pasado por revisión de pares, para asegurar que se cumplen las normas éticas, de calidad, validez científica, editorial e investigativa.

- Fomentar la divulgación de las investigaciones y actividades desarrolladas en la Universidad Católica de Colombia.
Palabras clave de la Revista de Arquitectura: arquitectura, diseño, educación arquitectónica, proyecto y construcción, urbanismo.

Idiomas de publicación: español, inglés, portugués y francés.

Título abreviado: Rev. Arquit.

\section{Titulo corto: RevArq}

\section{Políticas de sección}

La revista se estructura en tres secciones correspondientes a las líneas de investigación activas y aprobadas por la institución, y dos complementarias, que presentan dinámicas propias de la Facultad de Diseño y las publicaciones relacionadas con la disciplina.

Cultura y espacio urbano. En esta sección se publican los artículos que se refieren a fenómenos sociales en relación con el espacio urbano, atendiendo aspectos de la historia, el patrimonio cultural y físico, y la estructura formal de las ciudades y el territorio.

Proyecto arquitectónico y urbano. En esta sección se presentan artículos sobre el concepto de proyecto, entendido como elemento que define y orienta las condiciones proyectuales que devienen en los hechos arquitectónicos o urbanos, y la forma como estos se convierten en un proceso de investigación y nuevo de conocimiento. También se presentan proyectos que sean resultados de investigación, los cuales se validan por medio de la ejecución y transformación en obra construida del proceso investigativo. También se contempla la publicación de investigaciones relacionadas con la pedagogía y didáctica de la arquitectura, el urbanismo y el diseño.

Tecnología, medioambiente y sostenibilidad. En esta sección se presentan artículos acerca de sistemas estructurales, materiales y procesos constructivos, medioambiente y gestión, relacionados con los entornos social-cultural, ecológico y económico.

Desde la Facultad. En esta sección se publican artículos generados en la Facultad de Diseño, relacionados con las actividades de docencia, extensión, formación en investigación o internacionalización, las cuales son reflejo de la dinámica y de las actividades realizadas por docentes, estudiantes y egresados; esta sección no puede superar el $20 \%$ del contenido.

Textos. En esta sección se publican reseñas, traducciones y memorias de eventos relacionados con las publicaciones en Arquitectura y Urbanismo.

\section{Arecuencia de publicación}

Desde 1999 y hasta el 2015, la Revista de Arquitectura publicó un volumen al año, a partir del 2016 se publicarán dos números por año en periodo anticipado, enero-junio y julio-diciembre, pero también maneja la publicación anticipada en línea de los artículos aceptados (versión Post-print del autor).

La Revista de Arquitectura se divulga mediante versiones digitales (PDF, HTML, EPUB, XML) e impresas con un tiraje de 1.000 ejemplares, los tiempos de producción de estas versiones dependerán de los cronogramas establecidos por la editorial.

Los tiempos de recepción-revisión-aceptación pueden tardar entre seis y doce meses dependiendo del flujo editorial de cada sección y del proceso de revisión y edición adelantado.

Con el usuario y contraseña asignados, los autores pueden ingresar a la plataforma de gestión editorial y verificar el estado de revisión, edición o publicación del artículo.
(A) Canje

La Revista de Arquitectura está interesada en establecer canje con publicaciones académicas, profesionales o científicas del área de Arquitectura y Urbanismo, como medio de reconocimiento y discusión de la producción científica en el campo de acción de la publicación.

\section{Mecanismo}

Para establecer canje por favor descargar, diligenciar y enviar el formato: RevArq FP20 Canjes

Universidad Católica de Colombia (2018,
enero-junio).
Revista de Arquitectura, 20(I),
I-II6. Doi: 10.14718
ISSN: 1657-0308
E-ISSN: 2357-626X
Especificaciones:
Formato: $34 \times 24 \mathrm{~cm}$
Papel: Mate II5 g
Tintas: Negro y policromía

Contacto

Dirección postal:

Avenida Caracas No. 46-72.

Universidad Católica de Colombia

Bogotá D.C.(Colombia)

Código postal: 111311

Facultad de Diseño

Centro de Investigaciones (CIFAR).

Sede El Claustro. Bloque "L", 4 piso

Diag. 46 $\mathrm{a}$ No. $15 \mathrm{~b}-10$

Editor, Arq. César Eligio-Triana

Teléfonos:

+57 (1) $3277300-3277333$

Ext. 3109; 3112 o 5146

Fax: +57 (1) 2858895
Correo electrónico:

revistadearquitectura@ucatolica.edu.co cifar@ucatolica.edu.co

Página WEB www.ucatolica.edu.co vínculo Revistas científicas

http://publicaciones.ucatolica.edu.co/revistas-cientificas http://editorial.ucatolica.edu.co/ojsucatolica/revistas ucatolica/index.php/RevArq 


\section{Universidad Católica de Colombia}

Presidente

Édgar Gómez Betancourt

Vicepresidente - Rector

Francisco José Gómez Ortiz

Vicerrector Jurídico

Edwin de Jesús Horta Vásquez

Vicerrector Administrativo

Édgar Gómez Ortiz

Decano Académico

Elvers Medellín Lozano

Directora de Investigaciones

Elisa Urbina Sánchez

Directora Editorial

Stella Valbuena García

\section{Facultad de Diseño}

Decano

Werner Gómez Benítez

Director de docencia

Jorge Gutiérrez Martínez

Directora de extensión

Adriana Pedraza Pacheco

Director de investigación

Hernando Verdugo Reyes

Director de gestión de calidad

Augusto Forero La Rotta

Comité asesor externo

Facultad de Diseño

Édgar Camacho Camacho

Lorenzo Castro

Giovanni Ferroni Del Valle

Alberto Miani Uribe

Martha Luz Salcedo Barrera

Samuel Ricardo Vélez

\section{Facultad de Diseño
Centro de Investigaciones - CIFAR}

Revista de acceso abierto

arbitrada e indexada

Publindex: Categoría B. Índice Bibliográfico Nacional IBN.

Esci: Emerging Source Citation Index.

Doaj: Directory of Open Access Journals.

Redalyc: Red de Revistas Cientificas de América Latina y el Caribe,

España y Portugal.

Redib: Red Iberoamericana de Innovación y Conocimiento Cientifico.

Ebsco: EBSCOhost Research Databases.

Clase: Base de datos bibliográfica de revistas de ciencias sociales y humanidades.

Latindex: Sistema Regional de Información en Línea para Revistas Cientificas de América Latina, el Caribe, España y Portugal (Directorio y catálogo).

Dialnet: Fundación Dialnet - Biblioteca de la Universidad de La Rioja. LatinRev: Red Latinoamericana de Revistas Académicas en Ciencias

Sociales y Humanidades.

Proquest: ProQuest Research Library.

Miar: Matrix for the Analysis of Journals.

Sapiens Research: Ranking de las mejores revistas colombianas según

visibilidad internacional.

Actualidad Iberoamericana: (Indice de Revistas) Centro de Informacio

Tecnológica (CIT).

Google Scholar

Arla: Asociación de Revistas latinoamericanas de Arquitecturn

Editoria

Av. Caracas No 46-72, piso 5

Teléfono: 3277300 Ext. 5145

editorial@ucatolica.edu.co

www.ucatolica.edu.co

http://publicaciones.ucatolica.edu.co/

Impresión:

JAVEGRAF

Calle 46A No82-54 Int. 2

Bogotá, D. C., Colombia

http://www.javegraf.com.co/index.php

Abril de 2018

\section{Revista de Arquitectura}

Director

Werner Gómez Benítez

Editor

César Eligio-Triana

Editores de sección

(1) Myriam Stella Díaz Osorio

(1) Carolina Rodríguez Ahumada

(1) Anna Maria Cereghino Fedrigo

Consejo editorial

Werner Gómez Benítez

Jorge Gutiérrez Martínez

César Eligio-Triana

Hernando Verdugo Reyes

Equipo editorial

Coordinadora editorial

María Paula Godoy Casasbuenas

mpgodoy@ucatolica.edu.co

Diseño y montaje

Juanita Isaza

juanaisaza@gmail.com

Traductoras

Inglés

Erika Tanacs

etanacs25@gmail.com

Portugués

Roanita Dalpiaz

roanitad@gmail.com

Correctora de estilo

María José Díaz Granados M.

mariajose_dgm@yahoo.com.co

Página Web

Centro de investigaciones (CIFAR)

Distribución y canjes

Claudia Álvarez Duquino

calvarez@ucatolica.edu.co
Comité editorial y científico

Cultura y espacio urbano

Carlos Mario Yory, PhD

Universidad Católica de Colombia. Bogotá, Colombia

Sonia Berjman, PhD

ICOMOS-IFLA, Buenos Aires, Argentina

Juan Carlos Pérgolis, MSc Universidad Piloto de Colombia. Bogotá, Colombia

Beatriz García Moreno, PhD

Universidad Nacional de Colombia. Bogotá, Colombia

Proyecto arquitectónico y urbano

Jean-Philippe Garric, PhD, HDR

Université Paris I Panthéon-Sorbonne. Paris, Franci

Debora Domingo Calabuig, $\mathrm{PhD}$

Universidad Politécnica de Valencia, España

Dania González Couret, PhD

Universidad Tecnológica de La Habana, Cuba

Hugo Mondragón López, PhD

Pontificia Universidad Católica de Chile. Santiago, Chile

Juan Pablo Duque Cañas, PhD

Universidad Nacional de Colombia. Bogotá, Colombia

Tecnología, medioambiente y sostenibilidad

Mariano Vázquez Espí, PhD

Universidad Politécnica de Madrid, España

Denise Helena Silva Duarte, Dra Universidade de São Paulo (USP), Brasil

Luis Carlos Herrera Sosa, PhD Universidad Autónoma de Ciudad Juárez, México

Claudio Varini, PhD

Universidad Católica de Colombia. Bogotá, Colombia

Luis Gabriel Gómez Azpeitia, PhD Universidad de Colima. Colima, México 


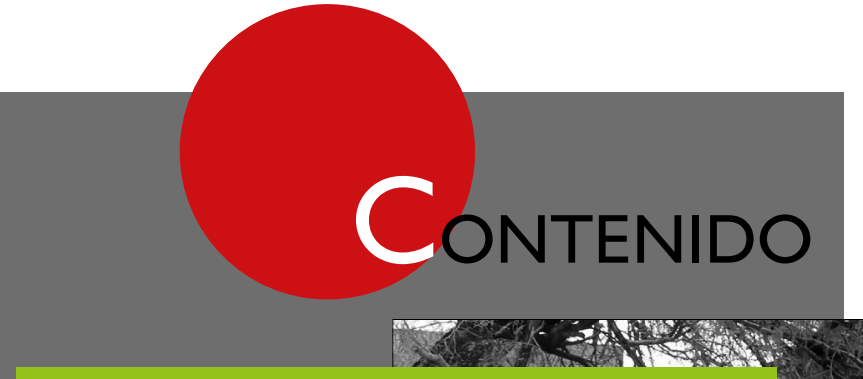

Cultura y espacio urbano

Culture and urban space Cultura e espaço urbano

14-37
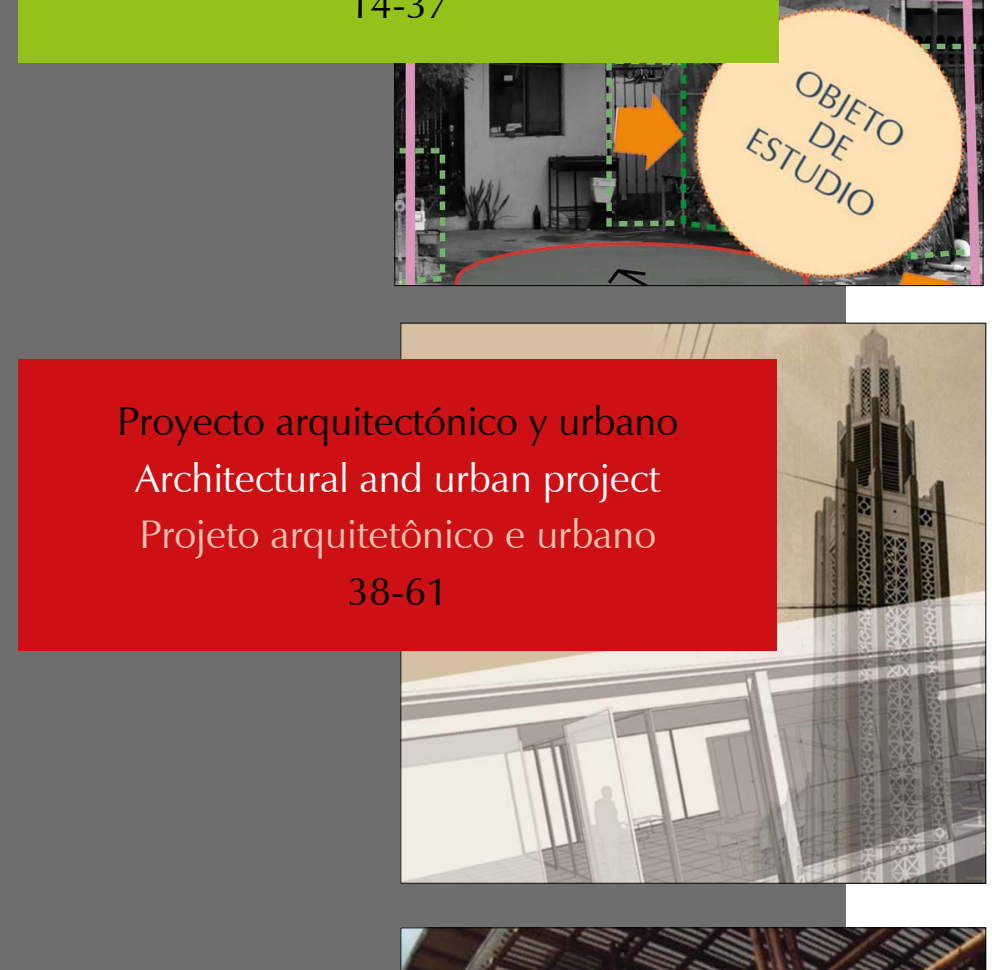

Tecnología, medioambiente y sostenibilidad

Technology, environment and sustainability Tecnologia, meio ambiente e sustentabilidad

$62-87$

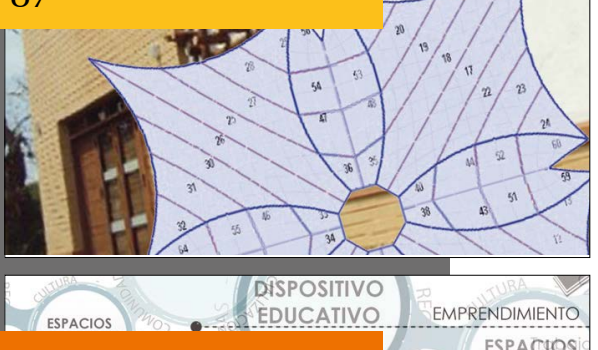

Desde la Facultad

From the Faculty

Da faculdade

88-101
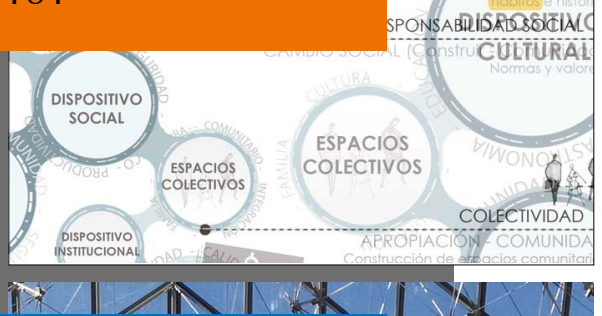

Textos

Texts

Textos

102-114

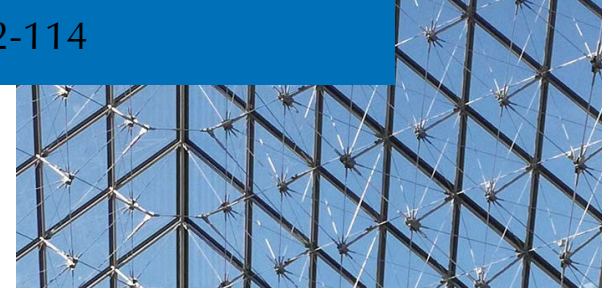

Editorial

El rol de las revistas de arquitectura y urbanismo en la divulgación del conocimiento

Participación e impacto de los SIR

César Eligio-Triana

Pág. 3

Las disputas por el sentido y sus lógicas de emplazamiento en la escena urbana neoliberal

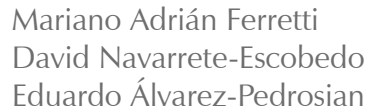

Mariano Adrián Ferretti

David Navarrete-Escobedo

Eduardo Álvarez-Pedrosian

La gestión urbana:

enseñanza a partir de sus proyecciones como campo de conocimiento y diálogo interdisciplinar

Fabián Andrés Llano

Pág. 24

Los años de formación de Alfonso Carvajal Escobar durante el periodo de entreguerras

Un ingeniero colombiano en la École des Beaux-Arts

\section{Andrés Ávila-Gómez}

\section{Daniel Jiménez-Atehortúa}

Pamela Londoño-Peralta

Plataforma desmaterializada en la casa Farnsworth Operación moderna estereotómica

Juan Fernando Valencia

Construcción de vivienda sostenible con bloques de suelo cemento: del residuo al material

Carlos Mauricio Bedoya-Montoya

Diseño y desarrollo de patrones de la forma de una tenso-estructura

Carlos César Morales-Guzmán

Pág. 71

Planteamiento de una estrategia desde la construcción de una investigación proyectual

$$
\begin{aligned}
& \text { Andrea Julieth Pava-Gómez } \\
& \text { María Alejandra Betancur-Villegas } \\
& \text { Angelo Páez-Calvo }
\end{aligned}
$$

Arquitectura, museos, turismo:

la guerra de las marcas

Maria Gravari-Barbas

Traductores

Andrés Ávila-Gómez

Diana Carolina Ruiz 


\section{suelo cemento: del residuo al material}

\section{Carlos Mauricio Bedoya-Montoya}

Universidad Nacional de Colombia Sede Medellín (Colombia)

Facultad de Arquitectura, Escuela de Construcción

Bedoya-Montoya, C. (2017). Construc ción de vivienda sostenible con bloques de suelo cemento: del residuo al material. Revista de Arquitectura, 20(I), 62-70. do http://dx.doi.org/10.14718/ RevArq.2018.20.I.II93

\section{(c) (1) $\Theta$}

http://dx.doi.org/10.14718/RevArq.2018.20.1.1193

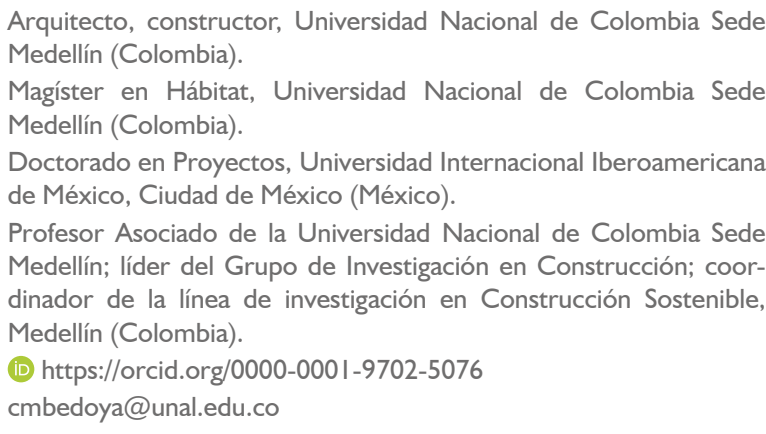

\section{Resumen}

El suelo producto de las excavaciones es visto generalmente como un residuo, cuyo tratamiento casi siempre es la disposición controlada en escombreras. Sin embargo, este puede ser valorizado como material de construcción mediante diferentes técnicas, entre ellas la confección de bloques de suelo cemento (BSC), con el empleo de la Cinva-Ram (prensa manual para la elaboración de bloques), la cual es de fácil manejo por parte del personal que se desempeña en el sector de la construcción. En tal sentido, se expone una experiencia basada en la valorización del suelo residual como material de óptimo desempeño y costo asequible para la construcción de vivienda. Este ejercicio experimental se realizó en el municipio de El Carmen de Viboral, departamento de Antioquia (Colombia), caracterizado por clima fresco con alto nivel de precipitaciones. Se realizaron diferentes mediciones que arrojaron como resultado que el desempeño físico-mecánico cumple con los requerimientos del proyecto, y las normas y reglamentaciones existentes, lo que es un aspecto a favor para la viabilidad de proyectos de vivienda que aporten a la sostenibilidad ecológica del hábitat mediante el concepto de minería a la inversa.

Palabras clave: Cinva-Ram, equilibrio ecológico, gestión de recursos, hábitat, material de construcción, minería a la inversa, sistemas constructivos.

\section{Sustainable house construction with soil cement blocks: From waste to} material

\section{Abstract}

Soil, as a product of excavations, is generally seen as waste, with a treatment that is almost always controlled disposal in waste dumps. However, it can be valued as a building material using different techniques, among them the elaboration of cement soil blocks (CSB) using Cinva-Ram (a manual press for making blocks), which is easy to handle by the staff who work in the construction sector. In this sense, this paper presents an experience based on the valorization of residual soil as an affordable material of optimum performance for housing construction. This experience was carried out in the geographical context of the department of Antioquia, Colombia, characterized by cool climate with high level of rainfalls. Different measurements showed that its physical-mechanical performance is in line with the requirements of the project, which is a favorable aspect for the viability of housing projects that contribute to the ecological sustainability of the habitat through the concept of inverse mining.

Keywords: Cinva-Ram, habitat, resource management, ecological balance, inverse mining, constructive systems.

\section{Construção de moradia sustentável com tijolos prensados de solo- \\ cimento: do resíduo ao material}

\section{Resumo}

O solo produto das escavações é visto, geralmente, como um resíduo, cujo tratamento quase sempre é a disposição controlada em escombreiras. Contudo, este pode ser valorizado como material de construção mediante diferentes técnicas, entre elas a confecção de tijolos de solo-cimento, com o emprego da CinvaRam (prensa manual para a fabricação de tijolos), a qual é de fácil manipulação por parte do pessoal que se desempenha no setor da construção. Nesse sentido, expõe-se uma experiência baseada na valorização do solo residual como material de ótimo desempenho e custo acessível para a construção de residências. Esse exercício experimental foi realizado no município de El Carmen de Viboral, estado de Antioquia (Colômbia), caracterizado por ter um clima fresco com alto nível de precipitações. Foram realizadas diferentes medições que demonstraram que o desempenho físico-mecânico cumpre com as solicitações do projeto e com as normas e regulamentações existentes, o que é um aspecto a favor da viabilidade de projetos de moradia que contribuam para a sustentabilidade ecológica do hábitat mediante o conceito de mineração inversa.

Palavras-chave: Cinva-Ram, equilíbrio ecológico, gestão de recursos, hábitat, material de construção, mineração inversa, sistemas 


\section{Introducción}

El resultado de este artículo hace parte del proyecto de investigación de Construcción Sostenible llevado a cabo en el marco de la línea que lleva el mismo nombre, y realizado en el Grupo de Investigación en Construcción de la Universidad Nacional de Colombia Sede Medellín. El objetivo del proyecto es permitir un ejercicio de reciprocidad entre el conocimiento de la academia y la aplicación en el medio a través de sus egresados. Como hipótesis se tiene que los lineamientos de construcción sostenible impartidos y trabajados en el aula de clase con estudiantes de pregrado y posgrado son susceptibles de ser aplicados posteriormente en el medio sin necesidad de leyes coercitivas u obligatorias, sino como resultado de un acto reflexivo de la actividad edificatoria en relación con el ecosistema que se va a intervenir.

Para la producción de bloque de suelo cemento (BSC) se requiere de una mezcla de suelo y cemento que generalmente es de 9:1 respectivamente, y de una prensa que comprime el material humedecido hasta obtener un mampuesto que, a catorce días de su confección, está en condiciones óptimas para ser instalado en la obra (NTC 5324 , 2005). Tal vez una de las mayores ventajas del BSC con respecto a otros prefabricados para mampostería es la posibilidad de ser producido en el sitio sin necesidad de instalaciones costosas con altos consumos de energía (Minke, 2005). Esta última cualidad permite inferir la pertinencia que tiene esta técnica para la construcción de proyectos de vivienda en zonas no urbanas, como es el caso del oriente cercano a la ciudad de Medellín, en cuyo territorio se viene dando un crecimiento del hábitat construido con una mirada poco reflexiva en cuanto a la materialización y vida útil del inmueble.

Municipios como Rionegro, El Carmen de Viboral y El Retiro, con unas condiciones de movilidad favorables entre poblaciones, han comenzado un proceso de urbanización que pareciera estar más destinado a la población externa con mayores ingresos que a los pobladores raizales; sin embargo, la experiencia reportada en este artículo muestra que estos últimos también pueden procurarse una vivienda asequible mediante la implementación de una construcción sostenible que propicie estrategias de bajo consumo de energía y de materiales durante la ejecución del proyecto y de la vida útil de este, como es el caso de la implementación de ecomateriales como los BSC, entre otros.

\section{Metodología}

En el marco de la línea de investigación en Construcción Sostenible, que contempla las cátedras electivas Construcción Sostenible ${ }^{1}$ y Estado del Arte de la Construcción Sostenible ${ }^{2}$, se abordan los fundamentos técnicos de materiales y sistemas constructivos de bajo impacto ambiental, como también las prácticas a nivel de laboratorio; sin embargo, queda pendiente la aplicación a escala real en el medio, por lo que el proyecto descrito en este artículo obedece a un ejercicio experimental de una vivienda unifamiliar construida en bloques de suelo cemento (BSC) mediante el uso de la Cinva-Ram, con énfasis en la aplicación de un sistema de muros parcialmente confinados. Aunque una parte de la vivienda se desarrolló en el sistema constructivo de bahareque encementado, el objeto de análisis de este trabajo es el BSC, ya que los tres muros construidos en bahareque obedecieron a una experimentación en un área de poca solicitación estructural de un nivel de altura. Se llevó a cabo un proceso de capacitación-concientización con los ayudantes, los oficiales y el maestro de la obra, específicamente en lo concerniente a la elaboración de la mezcla con suelo residual, manejo de la Cinva-Ram, curado de los BSC e instalación de estos para la conformación de los muros. Pues, aunque los procedimientos de mezclado, curado y colocación de los bloques son iguales a los de la mampostería tradicional, la implementación de un nuevo componente como el suelo residual y su elaboración con la prensa requieren de un acercamiento técnico y cultural.

Como materia prima para la elaboración de los bloques por emplear en la mampostería se escogió el suelo residual del corte del terreno y de las excavaciones, pues los ensayos básicos de consistencia y composición de este suelo arrojaron resultados positivos en cuanto a su distribución de limos, arcillas y arenas en función de producir in situ los BSC (Vásquez, Botero y Carvajal, 2015). El paso siguiente fue adquirir una prensa Cinva-Ram de operación manual con moldes para la producción de BSC aligerados tipo lego (Figura 6), con el fin de minimizar el consumo de material y el peso o las cargas muertas de la edificación; también, para utilizar los conductos que se dan en la mampostería como formaleta para el vaciado de la estructura de concreto reforzado de confinamiento, y para la distribución de instalaciones de acueducto, gas y redes eléctricas (Figuras 7 y 8).

\footnotetext{
1 Pregrado, código 3006721.
}

2 Posgrado, código 3010001. 
El diseño arquitectónico contempló la orientación de la vivienda en función del recorrido del sol para la iluminación natural durante gran parte del día y para permitir la entrada de sol a fin de generar un efecto invernadero artificial a pequeña escala y mantener una temperatura igual o mayor que la del exterior (Salazar, García y González, 2006), si se tiene en cuenta que el emplazamiento está a 2100 msnm y la temperatura promedio es de $17{ }^{\circ} \mathrm{C}$, además de un régimen de lluvias de $2000 \mathrm{~mm}$ anuales (Montoya y Montoya, 2009). Las cubiertas de la casa se pensaron como recolectoras de agua y se planteó una terraza técnica en la cual se ubicaron dos tanques de 1000 litros de capacidad cada uno para el almacenamiento de las aguas lluvia, un panel fotovoltaico para el sistema de iluminación y un calentador de agua de energía solar térmica. De esta manera, se diseñó un proyecto que contempló las siguientes variables:

- Fabricación de ecomateriales mediante la valorización del suelo residual (BSC y bahareque).

- Aprovechamiento de aguas Iluvia para usos no potables, que representan entre el 55 y el $65 \%$ del consumo en una vivienda (Cano, 2010).

- Iluminación con bombillas LED alimentadas mediante energía fotovoltaica.

- Calentamiento de agua con energía solar térmica.

- Uso de la guadua a nivel estructural.

- Minimización del uso de acabados arquitectónicos y de producción de escombros mediante la coordinación dimensional.

Con estas estrategias se concibió un proyecto de vivienda sostenible a lo largo de su ciclo de vida, teniendo en cuenta la ecoeficiencia en las etapas del diseño, la ejecución, la operación y el fin de la vida útil del inmueble, este último ítem referido a sus posibilidades de demolición selectiva o deconstrucción, reciclaje y reutilización de sus componentes. Para la puesta en marcha de este proyecto fue necesario implementar una planta in situ para la confección de los materiales y la producción de los BSC (Cubillos, Trujillo, Cortés, Rodríguez y Villar, 2014).

\section{Resultados}

\section{La construcción como metabolismo. Los flujos de energía y materiales}

$\mathrm{Al}$ emplear el principio de minería a la inversa se establece un flujo no lineal de energía y materiales que minimiza tanto la extracción de materias primas no renovables como la generación de residuos de construcción y demolición (RCD), su disposición controlada y la emisión de gases de efecto invernadero como el $\mathrm{CO}_{2}$ (Bedoya, 2013). El material producto del corte del terreno, del movimiento de las capas superficiales y de la excavación para las cimentaciones suele verse como un residuo y no como una materia prima potencial para la construcción, por lo que hay que invertir en costos de cargue del suelo residual, transporte y descargue en escombrera (Carvalho, Ramos, Zegarra y Pereira, 2016); a estos costos se suman aquellos en sentido contrario de cargue y transporte de materiales nuevos para la obra, como también los de adquisición de estos; adicionalmente, en ambos flujos se presenta un consumo de energía para el transporte y la confección de materiales nuevos, y una emisión de $\mathrm{CO}_{2}$ representada en la combustión de hidrocarburos utilizados en los vehículos transportadores y equipos de confección de ladrillos cerámicos y de concreto (Figura 1).

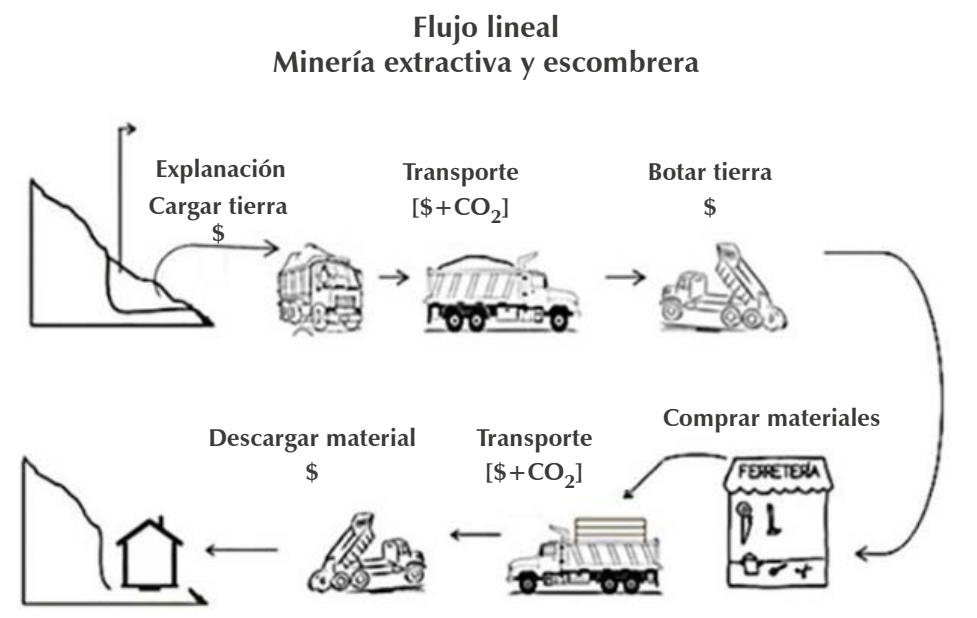

(A) Figura 1. Flujo lineal de materiales y RCD

Fuente: elaboración propia, 2015.
Flujo no lineal

Minería a la inversa - Ecomateriales

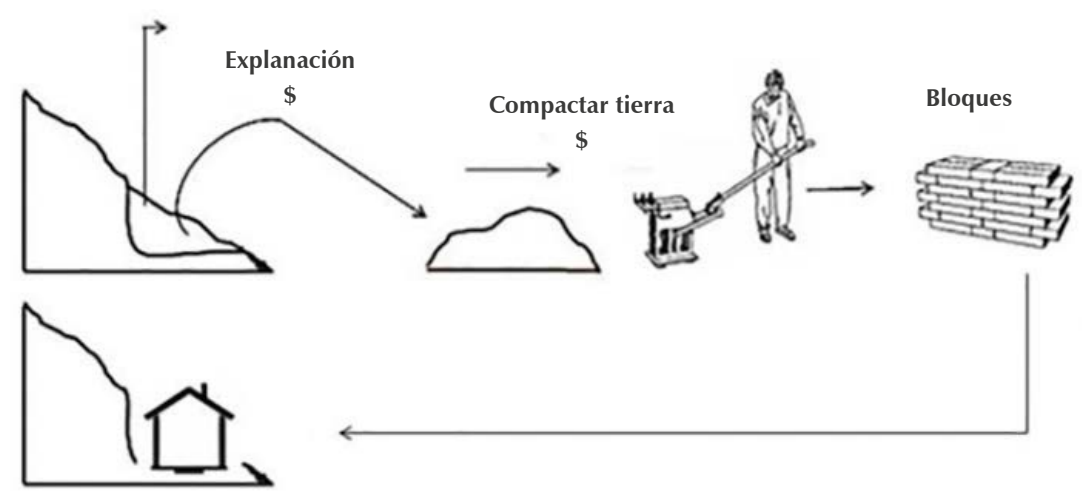

(A) Figura 2. Flujo no lineal de materiales y residuos. BSC in situ Fuente: elaboración propia, 2015. 


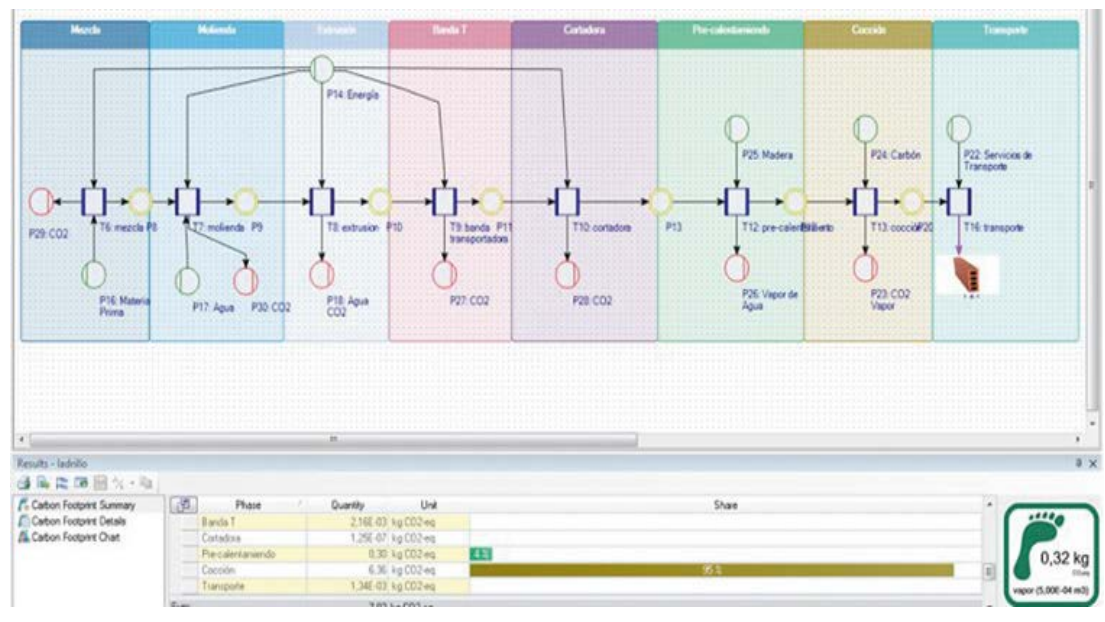

(4) Figura 3. Diagrama de Umberto NXT LCA para huella de $\mathrm{CO}_{2}$ (ladrillo cerámico)

Fuente: Captura de pantalla realizada por Herrera, 2015

\begin{tabular}{|c|c|}
\hline Muestra & $\begin{array}{l}\text { Huella de carbono } \\
\text { (kg CO2-eq) }\end{array}$ \\
\hline Ladrillo cerámico & 0,320 \\
\hline BSC & 0,00134 \\
\hline
\end{tabular}

(4) Tabla 1. Comparación de emisiones de $\mathrm{CO}_{2}$ entre $\mathrm{BSC}$ y ladrillo cerámico

Fuente: elaboración propia, 2015.
Al disponer de una planta de producción de materiales in situ (Figuras 4 y 5) se busca valorizar el suelo residual como material de construcción acorde con la norma técnica NTC 5324 (2005) del Icontec, y con el código de sismo-resistencia NSR-10 (Decreto 926 de 2010), para contribuir a una mirada más reflexiva sobre el ejercicio de la construcción de vivienda, por medio de la cual se disminuyen significativamente los pasivos ambientales -minería extractiva a cielo abierto, consumo de combustibles fósiles, emisiones de $\mathrm{CO}_{2}$, afectación paisajística por escombreras-, y se obtiene a cambio, como ejercicio recíproco entre el acto antrópico y la naturaleza, una disminución de los costos pagados en beneficio también de la viabilidad de los proyectos (Figura 2).

En la tabla 1 se muestra una comparación entre el BSC y el ladrillo cerámico en cuanto a huella de $\mathrm{CO}_{2}$; dicho análisis fue realizado empleando el software Umberto NXT LCA, licenciado por Ifu Hamburg( (e Alemania para la Universidad Nacional de Colombia Sede Medellín (Figura 3).

Según la tabla 1 se tiene que las emisiones de $\mathrm{CO}_{2}$ equivalente son 238 veces menos en el caso del BSC en comparación con el ladrillo cerámiCo, lo que coincide con otros estudios realizados en Francia por Craterre de la Unesco (Angulo, 2009). Para este análisis se tuvo en cuenta un contenido de cemento del $11,10 \%$ en peso, que es el caso más crítico para la Cinva-Ram manual, debido a que la huella de carbono del cemento Portland es un aspecto sensible en los materiales compuestos dado su proceso de producción basado en hornos tipo túnel con altas temperaturas $\left(1350\right.$ a $\left.1400{ }^{\circ} \mathrm{C}\right)$.

A continuación se muestran fotografías referidas a algunas de las características de la vivienda -diseñada y construida por los arquitectos Jorge Moreno e Isabel Correa, egresados de la Universidad Nacional de Colombia-, tales como tipo

\begin{tabular}{|c|c|}
\hline Ítem & Carmen de Viboral \\
\hline Altura (msnm) & 2100 \\
\hline Temperatura promedio $\left({ }^{\circ} \mathrm{C}\right)$ & 17 \\
\hline Lluvias promedio (mm/año) & 2000 \\
\hline Sistema constructivo & Mampostería confinada/muro tendinoso \\
\hline Área $\left(\mathrm{m}^{2}\right)$ & 170 \\
\hline BSC & Prensa Manual \\
\hline Cubierta & Madera protegida con chingle para ganancia térmica \\
\hline Calentamiento de agua & Energía solar térmica \\
\hline Iluminación/fuente & Lámparas LED/panel fotovoltaico \\
\hline Acueducto/Alcantarillado & Aguas Iluvia-acueducto municipal/Tratamiento in situ \\
\hline
\end{tabular}

de BSC y fachada (Figuras 4 a 9). Este proyecto fue construido para el año 2014 en un lote semiurbano ubicado en el municipio de El Carmen de Viboral, a 5 kilómetros de distancia del casco urbano de San Antonio de Pereira, perteneciente al municipio de Rionegro, por lo que el acceso de materiales y la vía principal se hizo por este sector del oriente antioqueño. Las condiciones climáticas y generales del proyecto se muestran en la tabla 2 .

\section{Aspectos técnicos}

En la Tabla 2 se muestra un listado con los datos técnicos relevantes de la construcción, tales como ficha técnica del sistema constructivo, fabricación de los BSC, resultados de resistencia al esfuerzo de la compresión a los 28 días de producidos y costos comparados con bloques convencionales de construcción.
(A) Tabla 2. Aspectos técnicos generales de la vivienda - El Fuente: elaboración propia, 2015. Carmen de Viboral 


\section{Resultados de laboratorio de los BSC}

La tabla 3 muestra los resultados de los ensayos realizados a los BSC en cuanto a resistencia al esfuerzo de la compresión a 28 días de edad, parámetro necesario para su empleo en construcciones acordes a la Norma de Sismo Resistencia (NSR-10).

Se puede observar que los BSC fabricados con la Cinva-Ram manual presentan un desempeño óptimo a la luz en los rangos de la tabla 3 de la NTC 5324, en la cual se establecen los valores exigidos para la resistencia a la compresión seca (Tabla 4).

Los BSC producidos manualmente en el proyecto El Carmen de Viboral cumplen con las exigencias de la NTC 5324, ya que se ubican en el rango BSC 40; se observa que ninguna de las muestras está por debajo de 0,8 veces el valor de la resistencia exigida, que sería igual a 3,2 MPa, y que la muestra de menor resistencia obtuvo un valor de 3,84 MPa (0,96 veces). Asimismo, el promedio de las resistencias de estas muestras fue de 3,98 MPa (0,995 veces), y si se eligen los dos valores menos alejados entre sí $(4,01$ MPa y 4,10 MPa) se obtiene un promedio de 4,055 MPa (1,01 veces). Estos bloques pueden ser empleados en paramentos, y pueden quedar expuestos, según numeral 1.6 de la NTC 5324; también se pueden utilizar como bloques accesorios para amarre, dinteles y columnas según numeral 1.4.3 de la misma NTC; también como formaleta para el vaciado de estructuras de concreto reforzado en sistemas de mampostería confinada, permitiendo la colocación de varillas de acero en los conductos formados por el traslape de los BSC y el posterior vaciado del concreto fluido para consolidar los pórticos (Figura 4).

Otras características para tener en cuenta fueron, además de la resistencia a la compresión, el peso por unidad y su densidad (Tabla 5).

Si bien el análisis de ciclo de vida para la huella de $\mathrm{CO}_{2}$ se hizo con un contenido crítico de cemento de $11,10 \%$ en peso, en la realidad en El Carmen de Viboral se trabajó con un 8\% (Tabla 6).

En el caso de esta experiencia se implementaron la coordinación dimensional y la valorización del suelo residual para confeccionar BSC in situ. Las medidas estándar para la coordinación dimensional fueron $30 \mathrm{~cm}$ de largo, $15 \mathrm{~cm}$ de espesor y $10 \mathrm{~cm}$ de alto, que son las medidas nominales del BSC, y se fabricaron medias piezas $(15 \mathrm{~cm}$ de largo, $15 \mathrm{~cm}$ de espesor y $10 \mathrm{~cm}$ de alto) para evitar cortes y con ello la genera-

\begin{tabular}{cccc} 
Bloques llenos & BSC & BSC & BSC \\
20 & 40 & 60 \\
Resistencia mínima $(\mathrm{R})$ para la fracción de 0,05 en MPa & 2 & 4 & 6 \\
\hline
\end{tabular}

(A) Tabla 3. Resistencia al esfuerzo de la compresión a 28 días

Fuente: elaboración propia, 2015.

\begin{tabular}{|c|c|}
\hline Muestras & $\begin{array}{c}\text { Resistencia al esfuerzo de } \\
\text { la compresión a } 28 \text { días (MPa) }\end{array}$ \\
\hline BSC 1 & 4,01 \\
\hline BSC 2 & 3,84 \\
\hline BSC 3 & 4,10 \\
\hline Promedio & 3,98 \\
\hline
\end{tabular}

(A) Tabla 4. Clases de resistencia a la compresión seca Fuente: NTC 5324 (2005).

\begin{tabular}{ccc} 
Muestras & Peso $(\mathbf{g})$ & Densidad $\mathbf{( g / \mathbf { c m } ^ { 3 } )}$ \\
BSC 1 & 6020 & 1,83 \\
\hline BSC 2 & 6013 & 1,83 \\
\hline BSC 3 & 6179 & 1,88 \\
\hline Promedio & $\mathbf{6 0 7 1}$ & $\mathbf{1 , 8 4}$ \\
\hline
\end{tabular}

(A) Tabla 5. Pesos y densidades de BSC de $15 \times 10 \times 30 \mathrm{~cm}$ con perforaciones verticales

Fuente: elaboración propia, 2015.

\begin{tabular}{ccc} 
Muestra & $\begin{array}{c}\text { Contenido de } \\
\text { cemento }(\mathbf{g})\end{array}$ & Costo USD/COP \\
\hline Carmen de Viboral & 449,00 & $0,084 / 245,00$ \\
\hline
\end{tabular}

A Tabla 6. Contenido de cemento por unidad y costo del material Fuente: elaboración propia, 2016.

ción de escombros por rotura, por lo que el acostumbrado $7 \%$ de desperdicio por bloques para muros no se tuvo en cuenta; además, en caso de una rotura del BSC por manipulación, este puede volverse a introducir en el ciclo productivo como agregado.

En el proyecto se concibe que la textura de los muros con BSC será parte del acabado tanto en exteriores como en interiores, por lo que los costos de revoque, estuco y pintura también se evitaron, siendo este un ítem importante en el costo global de cualquier proyecto, con un valor promedio de $8 \%$. En este caso se hizo una capacitación-concientización con la mano de obra de la mampostería, 
ya que es costumbre no abordar este aspecto constructivo con detalle porque "para eso están los acabados"; en ese sentido tampoco es válido decir que el rendimiento es menor, pues se estaría comparando con un proceso de ejecución más rápido pero con más desperfectos de horizontalidad y verticalidad (nivel y plomo, respectivamente, en el argot de la albañilería), que luego requiere de sobrecostos en rellenos con materiales costosos como el cemento, el estuco y las pinturas.

La mampostería en un sistema parcialmente confinado como el escogido en la construcción referenciada representa entre el 30 y el $35 \%$ del costo total de la vivienda (Cano, 2012), así que, al fabricar los bloques en el sitio de la obra, utilizando además RCD como materias primas, se impacta un porcentaje importante del costo global del proyecto dado que el BSC resulta más barato que la oferta de ladrillos cerámicos y de concreto en la región (Tabla 7).

Los costos del BSC suelen variar de acuerdo con la zona geográfica del emplazamiento y la composición del suelo, ya que algunas veces el material presenta las condiciones óptimas de limos, arcillas y arena, y otras hay que complementar la mezcla con un porcentaje de arena adquirido en canteras o depósitos. Para este artículo se trabajó con el precio más alto alcanzado hasta el momento en las experiencias desarrolladas por el autor y su grupo de trabajo, que es del orden del $75 \%$ del catalán cerámico y del $53 \%$ del catalán en concreto, aunque en experiencias desarrolladas en la zona del oriente cercano a Medellín, como en el municipio de Guarne, se alcanzaron costos menores (Bedoya, 2011).

Por último, se menciona el costo evitado del cargue, transporte y disposición del suelo residual del proyecto, pues al emplear un flujo no lineal o semicerrado de materiales y energía basado en la valorización de los RCD como material de construcción, el suelo removido y excavado se queda en la obra y pasa a ser una materia prima. No se paga entonces por cargue del suelo residual, ni por el transporte de ese suelo a la escombrera ni por la descarga. Es importante considerar que, en este tipo de construcciones, el transporte es más costoso porque al tratarse de zonas no del todo urbanas las velocidades de las volquetas son bajas y el consumo de combustible aumenta, por tanto, el kilómetro recorrido tiene una tarifa mayor, y eso es justo; además, el vertimiento o descargue en escombrera tiene un costo promedio de 50000 pesos por viaje. Con la valorización del suelo residual en el lugar de la obra también se evita la emisión de $\mathrm{CO}_{2}$ al ambiente al no tener que transportar este material a escombreras, si se tiene en cuenta que la producción de este gas de efecto invernadero en un vehículo en buenas condiciones es de 120 g/km (Fernández, Mosquera y Mosquera, 2010).

\section{Discusión}

\section{Construcción sostenible frente a construcción convencional: costos evitados (Bettini, 1998)}

En el gremio de la construcción es común contemplar desperdicios de materiales en porcentajes que van del 5 al $10 \%$ en los presupuestos globales de obra, también asumir como inevitables la disposición controlada o "botada" de escombros, el empleo de agua potabilizada para usos donde no se requiere de esta y la climatización mecánica de los ambientes. Pero al aplicar la construcción sostenible se entra en un campo de complejidad y pensamiento sistémico (Morin, 2007; Garciandía, 2005), por lo que los análisis de costos trascienden al precio unitario del producto terminado para involucrar los intangibles ambientales y sociales; por ello, en vez de hablar de desperdicio de materiales se habla de coordinación dimensional; la última alternativa que se analiza es la mecanización de los ambientes; la primera opción que se estudia es el uso inteligente del agua acorde con el contexto y con la legislación según Ley 373 de 1997; y la alternativa conceptual es la implementación de flujos no lineales de materiales y de energía durante y después de la ejecución del proyecto. Si bien la edificación de vivienda referenciada en este artículo contempla

\section{Bloque Catalán cerámico $15 \times 10 \times 30(\mathrm{~cm})$ USD/COP}

Bloque Catalán concreto $15 \times 10 \times 30(\mathrm{~cm})$ USD/COP
Bloque Suelo Cemento $15 \times 10 \times 30(\mathrm{~cm})$ USD/COP 
todas estas alternativas, el análisis principal de costos evitados está basado en la aplicación del concepto de minería a la inversa por medio de la valorización de RCD, entre los cuales el suelo residual es a veces el $55 \%$ del total de estos (ASOP-SMA, 2005).

Los resultados en cuanto al comportamiento físico-mecánico de los BSC se enmarcan en los rangos exigidos por las normas técnicas colombianas, lo que representa un hallazgo de cara a la consolidación de técnicas y tecnologías apropiadas al contexto del emplazamiento, aportando con ello a la obtención no solo de materias primas de costo asequible, bajo impacto ambiental y óptimo desempeño, sino también a la aceptación de diseños arquitectónicos y sistemas constructivos que, sin abandonar el rigor técnico, se comportan con mayor idoneidad en cuanto al confort y a las dinámicas socioculturales de la población inherente al proyecto, entre ellas, la aceptación de una estética de las formas y de la materialidad

Un aspecto relevante que arroja este trabajo es el cuestionamiento hacia las prácticas poco reflexivas llevadas a cabo en la construcción de proyectos de vivienda, en las cuales se remueve el suelo superficial bien sea por explanaciones, cortes o excavaciones, y se lleva a rellenos sanitarios o a escombreras como un residuo, por lo que hay que pagar, pero, posteriormente el proyecto debe adquirir este tipo de materiales para efectos de urbanismo o nivelación de terrenos, por lo que también tiene que pagar. Así, al no tener en cuenta el suelo residual como una posible materia prima susceptible de ser valorizada o intercambiada con obras vecinas se incurre en un doble gasto, en tanto que hay un flujo de salida (cargue, transporte y descarga en escombrera) de este tipo de RCD, y al mismo tiempo se configura un flujo de entrada de nuevos materiales (cargue, transporte y descarga en la obra), ambos con costos inherentes a sus procesos logísticos y energéticos.

\section{Conclusiones}

La vivienda para la población colombiana merece ser analizada no solo desde el punto de vista de la posesión del inmueble, sino también como espacio ideal para el habitar en condiciones de confort arquitectónico, ambiental y social, con la posibilidad de implementar sistemas constructivos, materiales y estrategias de diseño encaminados al uso racional de la energía y del agua. Esto referido no solo a la construcción de la edificación, sino también al periodo de vida útil que es el más dramáti- co, ya que representa lapsos de 40, 50 y hasta más años de usufructo, por lo que una incorrecta concepción de los espacios en relación con la iluminación natural acarreará consumos innecesarios de energía eléctrica en jornadas diurnas y sobre costos en la facturación mensual.

La implementación de técnicas y sistemas de recolección de aguas lluvia -en lugares con esta ventaja pluviométrica- permitirá desarrollar actividades diarias de alto consumo como el vaciado de aparatos sanitarios, trapeado, lavado de ropas, entre otros, que no requieren de agua potable. El aprovechamiento de aguas lluvia en viviendas propiciaría una rebaja en los egresos mensuales de la población por efectos de un menor costo de facturación, y también minimizaría los riesgos por inundaciones debidas a las escorrentías urbanas, ya que al tener cada vez más porciones de territorio con zonas duras poco permeables se hace necesaria la retención de los flujos hídricos para que no lleguen rápidamente a los afluentes.

De la experiencia expuesta en este artículo se puede inferir que es posible para una familia colombiana procurarse una vivienda que cumpla con las exigencias normativas de durabilidad y sismo-resistencia a menores costos que los propuestos por el ejercicio inmobiliario, con la aplicación del principio de la construcción sostenible, siendo incluso una opción más económica al momento de su ejecución en comparación con sistemas constructivos convencionales basados en flujos lineales -poco o nulamente reflexivos-. En el caso de las estrategias para la sostenibilidad que requieren una inversión inicial mayor, la tasa interna de retorno mostrará la viabilidad de estas como también el ahorro obtenido a lo largo de la vida útil de la construcción, por ejemplo, en los casos de paneles térmicos y fotovoltaicos, y en las redes hidrosanitarias para aprovechamiento de aguas Iluvia.

La confección de materiales de construcción bajo el enfoque de minería a la inversa representa una opción válida para la construcción de viviendas desde los aspectos técnicos, económicos, ambientales y estéticos. Los costos evitados, si bien en un principio favorecen al usuario y al constructor, son en realidad beneficios comunes para las colectividades si se analizan desde una perspectiva sistémica, ya que al no botar o disponer determinada cantidad de RCD en escombreras, se evitan la degradación de la corteza terrestre por la minería a cielo abierto para materias primas y la afectación biótica de los territorios que los alojan (Bedoya, 2003). 
Es factible para una familia de clase media construir una vivienda sin la obligatoriedad de un crédito a largo plazo con el empleo de técnicas y materiales de construcción asequibles geográficamente y de óptimo desempeño, ya que no solo hay un ahorro al momento de la ejecución del proyecto, sino que además se ahorra en consumos de energía y agua, lo que se traduce en menores egresos desde los primeros años del ciclo de vida de la vivienda, y, por ende, en una mayor capacidad de pago, por ejemplo, para otros sistemas de crédito de tipo solidario que manejan menores plazos y tasas de intereses. También es viable generar proyectos de VIS y VIP con materiales sostenibles y ecotécnicas que inciden significativamente en la canasta familiar, como ya se ha demostrado en México con el programa "Hipotecas verdes", liderado por el profesor David Morillón de la UNAM (2013).
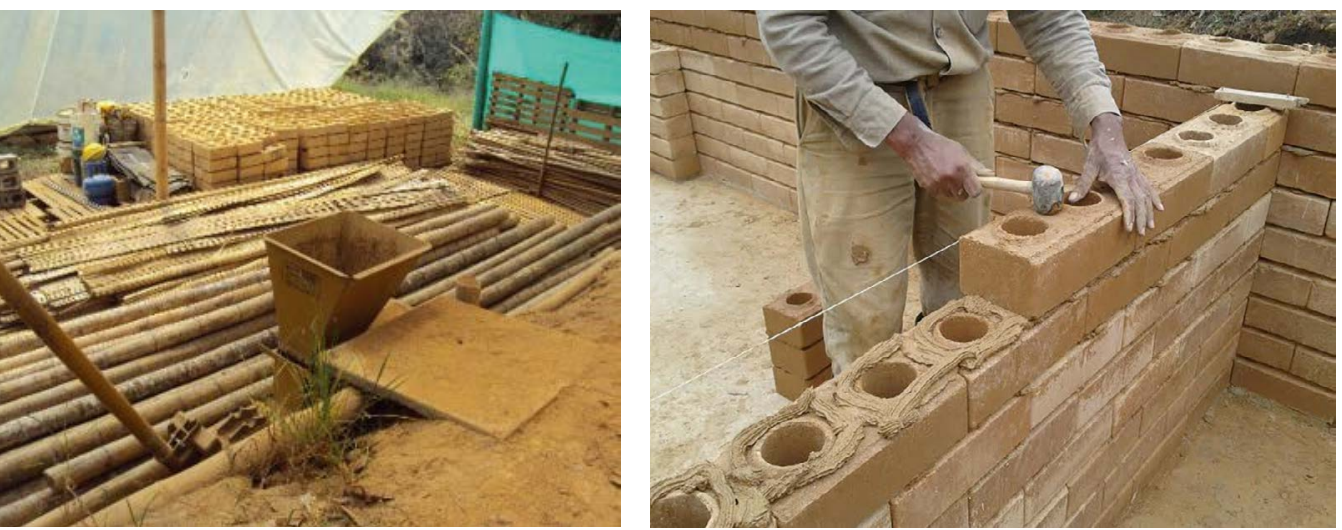

\section{Referencias}

Angulo, D. (2009). Construcción en bloque de tierra compactada (BTC). Alternativa de construcción en la arquitectura contemporánea. Revista Esphera, 1(3), 66-69. Recuperado de http://biblos.uamerica.edu.co/ cgi-bin/koha/opac-detail.pl?biblionumber $=444081$

ASOP-SMA (2005). Estudio para el diseño de valorización de residuos de escombros, mediante un sistema de gestión integral de los mismos para la producción más limpia en la ciudad de Medellín. Medellín: Secretaría de Medio Ambiente de Medellín.

Bedoya, C. (2003). El concreto reciclado con escombros como generador de hábitats urbanos sostenibles. La ciudad como ecosistema semi-cerrado, una utopía cultural. Tesis de Maestría en Hábitat. Universidad Nacional de Colombia. Medellín. Recuperado de http://www.bdigital.unal.edu. co/3477/1/98589947-2003.pdf

Bedoya, C. (2011). Viviendas de interés social y prioritario sostenibles en Colombia VISS y VIPS. Revista internacional de sostenibilidad, tecnología y humanismo, 6 27-36. Recuperado de http://hdl.handle. net/2099/11911

Bedoya, C. (2013). El concreto con agregados reciclados (CAR) y su gestión integral en un proyecto de viabilidad para el ecosistema urbano de Medellín. En X Encuentro Internacional de Hábitat Sostenible - Biocasa. Camacol, Cali, Valle.

Bettini, V. (1998). Elementos de ecología urbana. Madrid: Trotta.

Cano, E. (2010). Documento técnico de base para la elaboración de una política pública de construcción sostenible para el Valle de Aburrá. Medellín: AMVA.
Cano, E. (2012). Uso sostenible del agua en la construcción. En Seminario de Bioclimatismo aplicado a edificaciones. Manizales: Camacol Caldas.

Carvalho, M., Ramos, F., Zegarra, J. y Pereira, C. (2016). Evaluación a lo largo del tiempo de las propiedades mecánicas de los bloques de suelo-cemento utilizados en pavimentos semipermeables. Revista ingeniería de construcción, 31 (1), 61-70. https://dx.doi. org/10.4067/S0718-50732016000100006

Cubillos González, R., Trujillo, J., Cortés Cely, O., Rodríguez Álvarez, C. y Villar Lozano, M (2014). La habitabilidad como variable de diseño de edificaciones orientadas a la sostenibilidad. Revista de Arquitectura, 16 (1), 114-125. doi:http://dx.doi.org/10.14718/ RevArq.2014.16.13

Decreto 926 de 2010. Por el cual se establecen los requisitos de carácter técnico y científico para construcciones sismorresistentes NSR10. Marzo 19 de 2010. D.O. No. 47.656.

Fernández Henao, S., Mosquera A., J. y Mosquera M., J. (2010). Análisis de emisiones de CO² para diferentes combustibles en la población de taxis en Pereira y Dosquebradas. Scientia et technica, 2(45), 141-146. doi:http:// dx.doi.org/10.22517/23447214.385

Garciandía, J. (2005). Pensar sistémico: un introducción al pensamiento sistémico. Bogotá: Pontifica Universidad Javeriana.

Ley 373 de 1997. Por la cual se establece el programa para el uso eficiente y ahorro del agua. 11 de junio de 1997. D.O. No. 43.058.

Minke, G. (2005). Manual de construcción para viviendas antisísmicas de tierra. Alemania: Universidad de Kassel.
Montoya Moreno, Y. y Montoya Moreno, B (2009). Caracterización morfométrica de la microcuenca de la quebrada Los Andes, El Carmen de Viboral, Antioquia-Colombia. Revista Ingenierías Universidad de Medellín, 8(15), 31-38. Recuperado de http://revistas.udem.edu.co/index.php/ingenierias/ article/view/244

Morillón, D. (2013). Eficiencia energética para la construcción sustentable. En X Encuentro Internacional de Hábitat Sostenible - Biocasa. Cali: Camacol Valle.

Morin, E. (2007). Introducción al pensamiento complejo. Barcelona: Gedisa.

NSR-10 (2010). Ministerio de Ambiente, Vivienda y Desarrollo Territorial. Reglamento Colombiano de Construcciones Sismorresistentes, Capítulo D. Bogotá: Icontec.

NTC 5324. (2005). Bloques de suelo cemento para muros y divisiones. Definiciones. Especificaciones. Métodos de ensayo. Condiciones de entrega. Bogotá: Icontec.

Salazar, J., García A. y González, A. (2006). Labor Cero. Arquitectura a la medida. PVC Arquitectos. Medellín: Argos.

Vásquez Hernández, A., Botero Botero, L. y Carvajal Arango, D. (2015). Fabricación de bloques de tierra comprimida con adición de residuos de construcción y demolición como reemplazo del agregado pétreo convencional. Ingeniería y Ciencia, 11(21), 197. 220. doi:10.17230/ingciencia.11.21.10 
La postulación de un artículo a la Revista de Arquitectura indica que- el o los autores certifican que conocen y aceptan la política editorial, para lo cual firmarán en original y remitirán el formato RevArq FP00 Carta de originalidad.

La Revista de Arquitectura maneja una política de Autoarchivo VERDE, según las directrices de SHERPA/RoMEO, por lo cual el autor puede:

- Pre-print del autor: Archivar la versión pre-print (la versión previa a la revisión por pares)

- Post-print del autor: Archivar la versión post-print (la versión final posterior a la revisión por pares

- Versión de editor/PDF: Archivar la versión del editor - PDF/HTML/XLM en la maqueta de la Revista de Arquitectura.

El Autoarchivo se debe hacer respetando la licencia de acceso abierto, la integridad y la imagen de la Revista de Arquitectura, también se recomienda incluir la referencia, el vínculo electrónico y el DOI.

El autor o los autores son los titulares del Copyright (c) del texto publicado y la Editorial de la Revista de Arquitectura solicita la firma de una autorización de reproducción del artículo (RevArq FP03 Autorización reproducción), la cual se acoge a la licencia CC, donde se expresa el derecho de primera publicación de la obra.

La Revista de Arquitectura se guía por las normas internacionales sobre propiedad intelectual y derechos de autor, y de manera particular el artículo 58 de la Constitución Política de Colombia, la Ley 23 de 1982 y el Acuerdo 172 del 30 de septiembre de 2010 (Reglamento de propiedad intelectual de la Universidad Católica de Colombia).

Para efectos de autoría y coautoría de artículos se diferencian dos tipos: "obra en colaboración" y "obra colectiva". La primera es aquella cuya autoría corresponde a todos los participantes al ser fruto de su trabajo conjunto. En este caso, quien actúa como responsable y persona de contacto debe asegurar que quienes firman como autores han revisado y aprobado la versión final, y dan consentimiento para su divulgación. La obra colectiva es aquella en la que, aunque participan diversos colaboradores, hay un autor que toma la iniciativa, la coordinación y realización de dicha obra. En estos casos, la autoría corresponderá a dicha persona (salvo pacto en contrario) y será suficiente únicamente con su autorización de divulgación.

El número de autores por artículo debe estar justificado por el tema, la complejidad y la extensión, y no deberá ser superior a la media de la disciplina, por lo cual se recomienda que no sea mayor de cinco. El orden en que se enuncien corresponderá a los aportes de cada uno a la construcción del texto, se debe evitar la autoría ficticia o regalada. Si se incluyen más personas que trabajaron en la investigación se sugiere que sea en calidad de colaboradores o como parte de los agradecimientos. La Revista de Arquitectura respetará el número y el orden en que figuren en el original remitido. Si los autores consideran necesario, al final del artículo pueden incluir una breve descripción de los aportes individuales de cada uno de firmantes.

La comunicación se establece con uno de los autores, quien a su vez será el responsable de informar a los demás autores de las notificaciones emitidas por la Revista de Arquitectura.

En virtud de mantener el equilibro de las secciones y las mismas oportunidades para todos los participantes, un mismo autor puede postular dos o más artículos de manera simultánea; si la decisión editorial es favorable y los artículos son aceptados, su publicación se realizará en números diferentes.

\section{A Acceso abierto}

La Revista de Arquitectura, en su misión de divulgar la investigación y apoyar el conocimiento y la discusión en los campos de interés, proporciona acceso abierto, inmediato e irrestricto a su contenido de manera gratuita mediante la distribución de ejemplares impresos y digitales. Los interesados pueden leer, descargar, guardar, copiar y distribuir, imprimir, usar, buscar o referenciar e texto completo o parcial de los artículos o la totalidad de la Revista de Arquitectura.

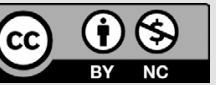

Esta revista se acoge a la licencia Creative Commons (CC BYNC de Atribución - No comercial 4.0 Internacional): "Esta licencia permite a otros entremezclar, ajustar y construir a partir de su obra con fines no comerciales, y aunque en sus nuevas creaciones deban reconocerle su autoría y no puedan ser utilizadas de manera comercial, no tienen que estar bajo una licencia con los mismos términos".

La Revista de Arquitectura es divulgada en centros y grupos de investigación, en bibliotecas y universidades, y en las principales facultades de Arquitectura, mediante acceso abierto a la versión digital y suscripción anual al ejemplar impreso o por medio de canje, este último se formaliza mediante el formato RevArq FP20 Canjes.

Para aumentar su visibilidad y el impacto de los artículos, se envían a bases de datos y sistemas de indexación y resumen (SIR) y, asimismo, pueden ser consultados y descargados en la página web de la revista.

La Revista de Arquitectura no maneja cobros, tarifas o tasas de publicación de artículo (Article Processing Charge-APC), o por el sometimiento de textos a la publicación.

\section{(1)Ética y buenas prácticas}

La Revista de Arquitectura se compromete a cumplir y respetar las normas éticas en todas las etapas del proceso de publicación. Los autores de los artículos publicados darán cumplimiento a los principios éticos contenidos en las diferentes declaraciones y legislaciones sobre propiedad intelectual y derechos de autor específicos del país donde se realizó la investigación. En consecuencia, los autores de los artículos postulados y aceptados para publicar, que presentan resultados de investigación, deben firmar la declaración de originalidad (formato RevArq FP00 Carta de originalidad).

La Revista de Arquitectura reconoce y adopta los principios de transparencia y buenas prácticas descritos por COPE, "Principles of Transparency and Best Practice in Scholarly Publishing" (2015).

El equipo editorial tiene la obligación de guardar la confidencialidad acerca de los artículos recibidos, y abstenerse de usar en sus propias investigaciones datos, argumentos o interpretaciones hasta tanto el artículo no sea publicado. También debe ser imparcial y gestionar los artículos de manera adecuada y en los plazos establecidos. La selección de revisores se hará con objetividad y estos deberán responder a la temática del artículo.

El editor, los autores y los revisores deben seguir las normas éticas internacionales definidas por el Committee on Publication Ethics (COPE), con el fin de evitar casos de:

- Fabricación, falsificación u omisión de datos.

- Plagio y autoplagio.

- Publicación redundante, duplicada o fragmentada.

- Omisión de referencias a las fuentes consultadas.

- Utilización de contenidos sin permiso o sin justificación.

- Apropiación individual de autoría colectiva.

- Cambios de autoría.

- Conflicto de interés (CDI) no revelado o declarado.

- Otras que pudieran surgir en el proceso de investigación y publicación. La fabricación de resultados se genera al mostrar datos inventados por los autores; la falsificación resulta cuando los datos son manipulados y cambiados a capricho de los autores; la omisión se origina cuando los autores ocultan deliberadamente un hecho o dato. El plagio se da cuando un autor presenta como ideas propias datos creados por otros. Los casos de plagio son los siguientes: copia directa de un texto sin entrecomillar o citar la fuente, modificación de algunas palabras del texto, paráfrasis y falta de agradecimientos; el autoplagio se da cuando el mismo autor reutiliza material propio que ya fue publicado, pero sin indicar la referencia al trabajo anterior. La revista se apoya en herramientas digitales que detectan cualquiera de estos casos en los artículos postulados, y es labor de los editores y revisores velar por la originalidad y fidelidad en la citación. La publicación redundante o duplicada se refiere a la copia total, parcial o alterada de un trabajo ya publicado por el mismo autor

En caso de sospechar de alguna mala conducta se recomienda seguir los diagramas de flujo elaborados por COPE (2008), con el fin de determinar las acciones correspondientes.

La Revista de Arquitectura se reserva el derecho de retractación de publicación de aquellos artículos que, posterior a su publicación, se demuestre que presentan errores de buena fe, o cometieron fraudes o malas prácticas científicas. Esta decisión se apoyará en "Retraction Guidelines" (COPE, 2009). Si el error es menor, este se podrá rectificar mediante una nota editorial de corrección o una fe de erratas. Los autores también tienen la posibilidad de solicitar la retractación de publicación cuando descubran que su trabajo presenta errores graves. En todos los casos se conservará la versión electrónica y se harán las advertencias de forma clara e inequívoca.

\section{(A) Privacidad y manejo de la información.} Habeas Data

Para dar cumplimiento a lo previsto en el artículo 10 del Decreto 1377 de 2013, reglamentario de la Ley 1581 de 2012, y según el Acuerdo 002 del 4 de septiembre de 2013 de la Universidad Católica de Colombia, "por el cual se aprueba el manual de políticas de tratamiento de datos personales":

La Universidad Católica de Colombia, considerada como responsable o encargada del tratamiento de datos personales, manifiesta que los datos personales de los autores, integrantes de los comités y pares revisores, se encuentran incluidos en nuestras bases de datos; por lo anterior, y en cumplimiento de las disposiciones legales vigentes, la Universidad solicitará siempre su autorización, para que en desarrollo de sus funciones propias como Institución de Educación Superior, en especial las relacionadas con la docencia, la extensión y la investigación, la Universidad Católica de Colombia pueda recolectar, recaudar, almacenar, usar, circular, suprimir, procesar, intercambiar, compilar, dar tratamiento, actualizar, transmitir o transferir a terceros países y disponer de los datos que le han suministrado y que han sido incorporados en las bases de datos de todo tipo que reposan en la Universidad.

La Universidad Católica de Colombia queda autorizada, de manera expresa e inequívoca, en los términos señalados por el Decreto 1377 de 2013, para mantener y manejar la información de nuestros colaboradores (autores, integrantes de los diferentes comités y pares revisores); así mismo, los colaboradores podrán ejercer sus derechos a conocer, actualizar, rectificar y suprimir sus datos personales, para lo cual se han dispuesto las siguientes cuentas de correo electrónico: 
La Revista de Arquitectura recibe artículos de manera permanente. Los artículos se procesan a medida que se postulan, dependiendo el flujo editorial de cada sección.

El idioma principal es el español, y como opcionales están definidos el inglés, el portugués y el francés; los textos pueden ser escritos y presentados en cualquiera de estos.

Los artículos postulados deben corresponder a las categorías universalmente aceptadas como producto de investigación, ser originales e inéditos y sus contenidos responder a criterios de precisión, claridad y brevedad.

Como punto de referencia se pueden tomar las tipologías y definiciones del Índice Bibliográfico Nacional, Publindex (2010) que se describen la continuación:

1. Artículo de revisión: documento resultado de una investigación terminada donde se analizan, sistematizan e integran los resultados de investigaciones publicadas o no publicadas, sobre un campo en ciencia o tecnología, con el fin de dar cuenta de los avances y las tendencias de desarrollo. Se caracteriza por presentar una cuidadosa revisión bibliográfica de por lo menos 50 referencias.
2. Artículo de investigación científica y tecnológica: documento que presenta, de manera detallada, los resultados originales de proyectos terminados de investigación. La estructura generalmente utilizada contiene cuatro apartes importantes: introducción, metodología, resultados y conclusiones.

3. Artículo de reflexión: documento que presenta resultados de investigación terminada desde una perspectiva analítica, interpretativa o crítica del autor, sobre un tema específico, recurriendo a fuentes originales.

En todos los casos se debe presentar la información suficiente para que cualquier investigador pueda reproducir la investigación y confirmar o refutar las interpretaciones defendidas.

También se pueden presentar otro tipo de documentos diferentes a los anteriormente descritos, como pueden ser: artículo corto, reporte de caso, revisión de tema, documento resultado de la revisión crítica de la literatura sobre un tema en particular, cartas al editor, traducción, documento de reflexión no derivado de investigación, reseña bibliográfica, así como proyectos de arquitectura o urbanismo, entre otros

\section{A Instrucciones para postular artículos}

Postular el artículo en la página web de la Revista de Arquitectura y ad-juntar comunicación escrita dirigida al editor RevArq FP00 Carta de originalidad (debidamente firmada por todos los autores en original); de igual manera, se debe diligenciar el formato de hoja de vida RevArq FP01 Hoja de Vida (una por cada autor).

En la comunicación escrita el autor expresa que conoce y acepta la política editorial de la Revista de Arquitectura, que el artículo no está postulado para publicación simultáneamente en otras revistas u órganos editoriales y que no existe conflicto de intereses (ver modelo RevArq FP06 CDI) y que, de ser aceptado, concederá permiso de primera publicación, no exclusiva a nombre de la Universidad Católica de Colombia como editora de la revista.

Los artículos deben tener en cuenta las siguientes recomendaciones:

- En la primera página del documento se debe incluir:

TíTULO: no exceder 15 palabras.

Subtítulo: opcional, complementa el título o indica las principales subdivisiones del texto.

Nombre del autor o autores: nombres y apellidos completos o según modelo de citación adoptado por el autor para la normalización de los nombres del investigador. Como nota al pie (máximo 150 palabras): formación académica, experiencia profesional e investigativa, vinculación laboral, código ORCID, premios o reconocimientos, publicaciones representativas e información de contacto, correo electrónico.

Filiación institucional: debajo del nombre se debe declarar la ins-titución en la cual se desarrolló el producto, de la cual recibió apoyo o aquella que respalda el trabajo investigativo.

Resumen: debe ser analítico, se redacta en un solo párrafo, da cuenta del tema, el objetivo, la metodología, los resultados y las conclusiones; no debe exceder las 150 palabras.

Palabras clave: cinco palabras o grupo de palabras, ordenadas alfabéticamente y que no se encuentren en el título o subtítulo; estas sirven para clasificar temáticamente al artículo. Se recomienda emplear principalmente palabras definidas en el tesauro de la Unesco (http:// databases.unesco.org/thessp/), en el tesauro de Arte \& Arquitectura (c) (www.aatespanol.cl), o Vitruvio (http://vocabularyserver.com/vitruvio/)

También se recomienda incluir título, resumen y palabras clave en segundo idioma.

- La segunda página y siguientes deben tener en cuenta

El cuerpo del artículo se divide en: Introducción, Metodología, Resultados y Discusión de resultados; posteriormente se presentan las Conclusiones, y luego las Referencias bibliográficas y los Anexos (método IMRYD). Las tablas y figuras se deben incorporar en el texto.

Descripción del proyecto de investigación: en la introducción se debe describir el tipo de artículo y brevemente el marco investigativo del cual es resultado y diligenciar el formato (RevArq FP02 Info Proyectos de Investigación).

TEXTO: todas las páginas deben venir numeradas y con el título de artículo en la parte superior de la página. Márgenes de $3 \mathrm{~cm}$ por todos los lados, interlineado doble, fuente Arial o Times New Roman de 12 puntos, texto justificado (Ver plantilla para presentación de artículos). La extensión de los artículos debe ser de alrededor de 5.000 palabras $( \pm 20$ páginas, incluyendo gráficos, tablas, referencias, etc.); como mínimo 3.500 y máximo 8.000 palabras. Se debe seguir el estilo vigente y recomendado en el Manual para Publicación de la American Psychological Association (APA). (Para mayor información véase http://www.apastyle.org)
Citas y notas al pie: las notas aclaratorias o notas al pie no deben exceder cinco líneas o 40 palabras, de lo contrario estas deben ser incorporadas al texto general. Las citas pueden ser:

Corta: (con menos de 40 palabras) se incorporan al texto y pueden ser: textuales (se encierran entre dobles comillas), parafraseo o resumen (se escriben en palabras del autor dentro del texto).

Cita textual extensa: (mayor de 40 palabras) debe ser dispuesta en un renglón y un bloque independiente con sangrías y omitiendo las comillas, no olvidar en ningún caso la referencia del autor (Apellido, año, página).

Referencias: como modelo para la construcción de referencias se emplea el estilo recomendado en el Manual para Publicación de la American Psychological Association (APA) (http://www.apastyle.org/).

Siglas: en caso de emplear siglas en el texto, las figuras o las tablas, se debe proporcionar la equivalencia completa la primera vez que se empleen y encerrarlas entre paréntesis. En el caso de citar personajes reconocidos se deben colocar nombres o apellidos completos, nunca emplear abreviaturas.

Figuras y tablas: las figuras (gráficos, diagramas, ilustraciones, planos, mar a deben ir numeradas y contener título o leyenda explicativa relacionada con el tema del artículo, que no exceda las 15 palabras (Figura 1. xxxxx, Tabla 1. xxxx, etc.) y la procedencia (fuente: autor o fuente, año, página). Estas se deben referenciar en e texto de forma directa o entre paréntesis; se recomienda hacerlo con referencias cruzadas.

También se deben entregar en medio digital, independiente del tex-to, en formatos editables o abiertos. La marcación de los archivos debe corresponder a la incluida en el texto. Según la extensión del artículo se deben incluir de 5 a 10 gráficos. Ver guía para la búsqueda de imágenes de dominio público o bajo licencias Creative Commons (CC).

El autor es el responsable de adquirir los derechos o las autorizaciones de reproducción a que haya lugar para imágenes o gráficos tomados de otras fuentes, así como de entrevistas o material generado por colaboradores diferentes a los autores; de igual manera, se debe garantizar la protección de datos e identidades para los casos que sea necesario.

FotoGRAFía: pueden ser entregadas en original para ser digitalizadas, de lo contrario se deben digitalizar con una resolución igual o superior a 300 dpi para imágenes a color y 600 para escala de grises. Los formatos de las imágenes pueden ser TIFF, PSD o JPG, y deben cumplir con las características expresadas en el punto anterior (figuras).

Planimetría: se debe entregar la planimetría original en medio digital, en lo posible en formato CAD, y sus respectivos archivos de plumas o en PDF; de no ser posible, se deben hacer impresiones en tamaño carta con las referencias de los espacios mediante numeración y lista adjunta. Deben tener escala gráfica, escala numérica, norte, coordenadas y loca-lización. En lo posible, no deben contener textos, achurados o tramas.

Para más detalles, consultar el documento RevArq Parámetros para Autores Descripción en el portal web de la Revista de Arquitectura

\section{Beneficios}

Como reconocimiento a los autores, se les hará envío postal de dos ejemplares de la edición impresa sin ningún costo y entregada en la dirección consignada en el formato de hoja de vida (RevArq FP01); adicionalmente, se enviará el vínculo para la descarga de la versión digital.

También se enviará una constancia informativa en la que se relaciona a publicación del artículo y, de manera opcional, se pueden detallar las fechas del proceso editorial y el arbitraje realizado. 
La selección de revisores se realiza de acuerdo con los siguientes criterios:

- Afinidad temática.

- Formación académica.

- Experiencia investigativa y profesional.

- Producción editorial en revistas similares o en libros resultado de investigación.

El proceso de arbitraje se basa en los principios de equidad e imparcialidad, y en los criterios de calidad y pertinencia.

El desarrollo de la revisión se realiza según el formato (RevArq FP10 Evaluación de artículos) y las observaciones que el revisor considere necesarias en el cuerpo del artículo. En cualquiera de los conceptos que emita el revisor (Aceptar, Publicable con modificaciones, Reevaluable o No publicable), y como parte de la labor formativa y de comunidad académica, el revisor hará sugerencias para mejorar el documento. El revisor podrá solicitar una nueva relectura del artículo después de los ajustes realizados por el autor.

El revisor también deberá diligenciar el formato RevArq FP01 Hoja de Vida, con el fin de certificar y soportar el proceso de revisión ante los SIR que así lo soliciten.

En el proceso de arbitraje se emplea el método doble ciego, los nombres del revisor no serán conocidos por el autor y viceversa. Con el fin de garantizar el anonimato del autor, al artículo postulado se le han podido suprimir nombres, instituciones o imágenes que puedan ser asociadas de manera directa al autor.

Aunque se procura el anonimato, una vez recibida la invitación como par revisor del artículo, el revisor debe cerciorarse de que no exista conflicto de intereses (CDI) o alguna limitante que afecte la revisión o que pueda ser vista como tal (lazos familiares, amistad o enemistad, vínculos contractuales o laborales, posiciones éticas, etc.), de presentarse esta situación se notificara al editor. (Ver modelo RevArq FP06 CDI).

Dada la confidencialidad del proceso de revisión, y considerando los derechos de autor y de propiedad intelectual que pueda haber sobre el material que se entrega, el revisor se compromete a mantener en absoluta reserva su labor, a limitar el uso de la obra entregada solo para el propósito designado y a devolver la documentación remitida una vez concluya la actividad.

El tiempo establecido para las revisiones de pares es de máximo un mes a partir de la confirmación de la recepción de la documentación. Ese plazo podrá ser modificado de mutuo acuerdo entre el editor y el revisor, siempre y cuando no afecte la periodicidad de la revista, la impresión o el tiempo para emitir una respuesta al autor.

Los revisores se acogerán a "COPE Ethical Guidelines for Peer Reviewers" de COPE.

\section{Beneficios}

Como retribución a los revisores se les hará envío postal de un ejemplar de la edición impresa sin ningún costo y entregada en la dirección consignada en el formato de hoja de vida. También, si es de interés para el revisor, podrá hacer la solicitud de alguna de las publicaciones editadas y presentes en el catálogo de publicaciones de la UNIVERSIDAD CATÓLICA DE COLOMBIA, previa aprobación de la Editorial y sujeto a la disponibilidad.

Si lo desea tendrá derecho a una constancia de la colaboración en la revisión de artículos, la cual solo contendrá el periodo en el cual se realizó la actividad. También tendrá la posibilidad de aceptar o no la publicación de su nombre, nacionalidad y nivel máximo de formación en la página web de la Revista de Arquitectura en su calidad de colaborador.

\section{A Proceso de revisión por pares}

Luego de la postulación del artículo, el editor de la Revista de Arquitec tura selecciona y clasifica los artículos que cumplen con los requisitos establecidos en las directrices para los autores. El editor podrá rechazar en primera instancia artículos, sin recurrir a un proceso de revisión, si los considera de baja calidad o por presentar evidencias de faltas éticas o documentación incompleta.

Los artículos se someterán a un primer dictamen del editor, de los editores de sección y del Comité Editorial, teniendo en cuenta:

- Afinidad temática, relevancia del tema y correspondencia con las secciones definidas.

- Respaldo investigativo.

- Coherencia en el desarrollo del artículo, así como una correcta redacción y ortografía.

- Relación entre las figuras y tablas con el texto del artículo.
En esta revisión se verificará el nivel de originalidad mediante el uso de software especializado (Ithenticate o similar) y recursos digitales existentes para tal fin, también se observará la coherencia y claridad en los apartados del documento (modelo IMRYD), la calidad de las fuentes y la adecuada citación, esto quedará consignado en el formato (RevArq FP09 Revisión de artículos); esta información será cargada a la plataforma de gestión editorial y estará a disposición del autor.

En caso de que el artículo requiera ajustes preliminares, será devuelto al autor antes de ser remitido a revisores. En este caso, el autor tendrá veinte días para remitir nuevamente el texto con los ajustes solicitados.

Después de la preselección se asignan mínimo dos revisores especializados, quienes emitirán su concepto utilizando el formato (RevArq FP10 Evaluación de artículos) y las anotaciones que consideren oportunas en el texto; en esta etapa se garantizará la confidencialidad y el anonimato de autores y revisores (modalidad doble ciego).

Del proceso de revisión se emite uno de los siguientes conceptos que será reportado al autor:

- Aceptar el envío: con o sin observaciones.

- Publicable con modificaciones: se podrá sugerir la forma más adecuada para una nueva presentación, el autor puede o no aceptar las observaciones según sus argumentos. Si las acepta, cuenta con quince días para realizar los ajustes pertinentes.

- Reevaluable: cumple con algunos criterios y debe ser corregido. Es necesario hacer modificaciones puntuales y estructurales al artículo. En este caso, el revisor puede aceptar o rechazar hacer una nueva lectura del artículo luego de ajustado.

- No publicable: el autor puede volver a postular el artículo e iniciar nuevamente el proceso de arbitraje, siempre y cuando se evidencien los ajustes correspondientes.

En el caso de presentarse diferencias sustanciales y contradictorias en los conceptos sobre la recomendación del revisor, el editor remitirá el artículo a un revisor más o a un miembro del Comité Editorial quien podrá actuar como tercer árbitro, con el fin de tomar una decisión editorial sobre la publicación del artículo.

Los autores deberán considerar las observaciones de los revisores o de los editores, y cada corrección incorporada u omitida debe quedar justificada en el texto o en una comunicación adjunta. En el caso que los autores omitan las indicaciones realizadas sin una argumentación adecuada, el artículo será devuelto y no se dará por recibido hasta que no exista claridad al respecto.

El editor respetará la independencia intelectual de los autores y a estos se les brindará el derecho de réplica en caso de que los artículos hayan sido evaluados negativamente y rechazados.

Los autores, con su usuario y contraseña, podrán ingresar a la plataforma de Gestión Editorial, donde encontrarán los conceptos emitidos y la decisición sobre el artículo.

El editor y el Comité Editorial se reservan el derecho de aceptar o no la publicación del material recibido. También se reservan el derecho de sugerir modificaciones de forma, ajustar las palabras clave o el resumen y de realizar la corrección de estilo. El autor conocerá la versión final del texto antes de la publicación oficial del mismo.

Cuando un artículo es aceptado para su publicación, el autor debe firmar la autorización de reproducción (RevArq FP03 Autorización reproducción). Para más información ver: Política de derechos de autor

\section{Notas aclaratorias:}

La Revista de Arquitectura publica un número limitado de artículos por volumen y busca el equilibrio entre las secciones, motivo por el cual, aunque un artículo sea aceptado o continúe en proceso de revisión, podrá quedar aplazado para ser publicado en un próximo número; en este caso, el autor estará en la posibilidad de retirar la postulación del artículo o de incluirlo en el banco de artículos del próximo número.

El editor y los editores de sección de la Revista de Arquitectura son los encargados de establecer contacto entre los autores y revisores, ya que estos procesos se realizan de manera anónima.
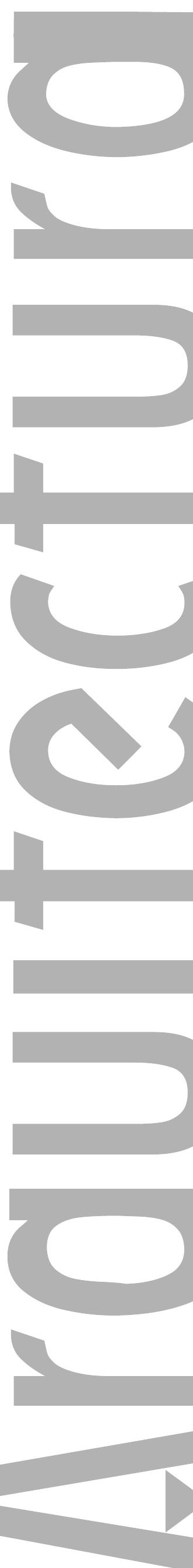
El rol de las revistas de arquitectura y urbanismo en la divulgación m del conocimiento. Participación e impacto de los SIR

$\cup$ The role of journals of architecture and urban planning in the dissemination of

¿ knowledge. Participation and impact of SIA

A gestão urbana: ensino a partir de suas projeções como campo de

conhecimento e diálogo interdisciplinar

Las disputas por el sentido y sus lógicas de emplazamiento en la \pm escena urbana neoliberal

(ن) Disputes over meaning and its logics of location in the neoliberal urban setting

As disputas pelo sentido e suas lógicas de localização no cenário urbano neolibera

\section{Mariano Adrián Ferreti}

David Navarrete-Escobedo

Eduardo Álvarez-Pedrosian

La gestión urbana: enseñanza a partir de sus proyecciones como ¿ campo de conocimiento y diálogo interdisciplinar

Urban management: Teaching based on its consideration as a field of

\& knowledge and interdisciplinary dialogue

A gestão urbana: ensino a partir de suas projeções como campo de conhecimento e diálogo interdisciplinar

Fabián Andrés Llano.

Los años de formación de Alfonso Carvajal Escobar durante el $\infty$ periodo de entreguerras. Un ingeniero colombiano en la École $\stackrel{\infty}{m}$ des Beaux-Arts

ن The formative years of Alfonso Carvajal Escobar during the interwar period.

A Colombian engineer at the École des Beaux-Arts

Os anos de formação de Alfonso Carvajal Escobar durante o período de entreguerras. Um engenheiro colombiano na École des Beaux-Arts

\section{Andrés Ávila-Gómez}

Daniel Jiménez-Atehortúa

Plataforma desmaterializada en la casa Farnsworth. Operación m moderna estereotómica

(1) Dematerialized platform in the Farnsworth house. A modern stereotomic

¿ operation

Plataforma desmaterializada na casa Farnsworth. Operação moderna estereotômica

Juan Fernando Valencia-Granda

Construcción de vivienda sostenible con bloques de suelo ู cemento: del residuo al material

ن Sustainable house construction with soil cement blocks: From waste to material

¿ Construção de moradia sustentável com tijolos prensados de solo-cimento: do resíduo ao material

Diseño y desarrollo de patrones de la forma de una tenso- estructura

- Design and pattern development of the shape of a tense structure

ن Desenho e desenvolvimento de padrões da forma de uma tensoestrutura

Planteamiento de una estrategia desde la construcción de una $\infty$ investigación proyectual

ن Proposal of a strategy based on the construction of a project research

Proposta de uma estratégia a partir da construção de uma pesquisa projetual

María Alejandra Betancur-Villegas

Angelo Páez-Calvo

Arquitectura, museos, turismo: la guerra de las marcas

$\mathcal{O}$ Architecture, museums, tourism: The war of brands

Arquitetura, museus, turismo: a guerra das marcas

这

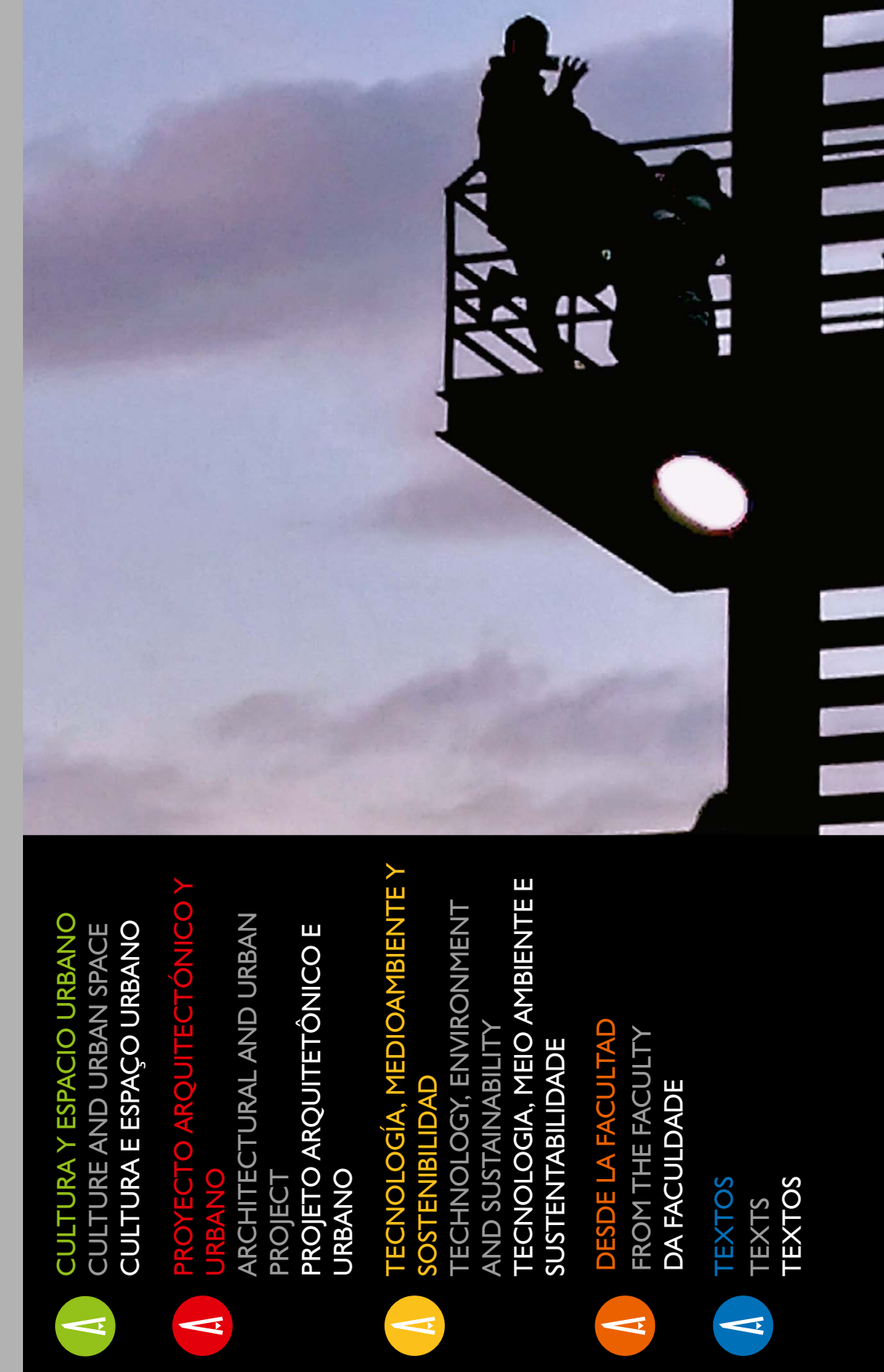

La Revista de Arquitectura es de acceso abierto, arbitrada e indexada y está presente en:
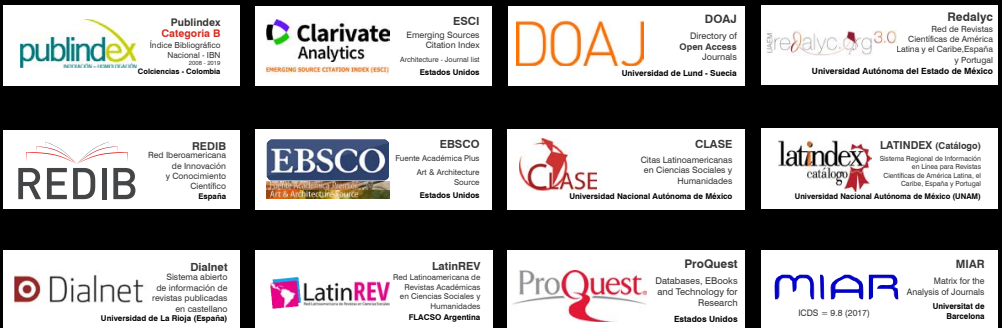

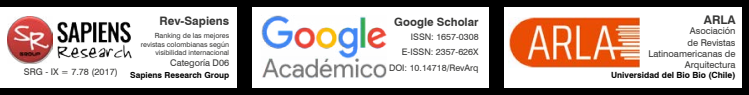

If Revista de Arquitectura Universidad Catolica de Colombia @ReVArqUCATOLICA
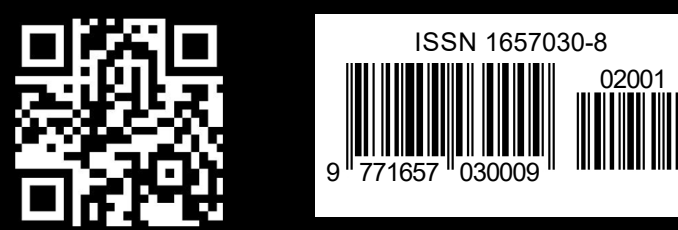